Article

\title{
Frequency Scan-Based Mitigation Approach of Subsynchronous Control Interaction in Type-3 Wind Turbines
}

\author{
Faris Alatar *(D) and Ali Mehrizi-Sani (D) \\ Bradley Department of Electrical and Computer Engineering, Virginia Polytechnic Institute and State University, \\ Blacksburg, VA 24061, USA; mehrizi@vt.edu \\ * Correspondence: afaris@vt.edu
}

Citation: Alatar, F.; Mehrizi-Sani, A. Frequency Scan-Based Mitigation Approach of Subsynchronous Control Interaction in Type-3 Wind Turbines. Energies 2021, 14, 4626. https:// doi.org/10.3390/en14154626

Academic Editor: Davide Astolfi

Received: 4 July 2021

Accepted: 28 July 2021

Published: 30 July 2021

Publisher's Note: MDPI stays neutral with regard to jurisdictional claims in published maps and institutional affiliations.

Copyright: (C) 2021 by the authors. Licensee MDPI, Basel, Switzerland. This article is an open access article distributed under the terms and conditions of the Creative Commons Attribution (CC BY) license (https:// creativecommons.org/licenses/by/ $4.0 /)$.

\begin{abstract}
Integration of wind energy resources into the grid creates several challenges for power system dynamics. More specifically, Type-3 wind turbines are susceptible to subsynchronous control interactions (SSCIs) when they become radially connected to a series-compensated transmission line. SSCIs can cause disruptions in power generation and can result in significant damage to wind farm (WF) components and equipment. This paper proposes an approach to mitigate SSCIs using an online frequency scan, with optimized phase angles of voltage harmonic injection to maintain steady-state operation, to modify the controllers or the operating conditions of the wind turbine. The proposed strategy is simulated in PSCAD/EMTDC software on the IEEE second benchmark model for subsynchronous resonance. Simulation results demonstrate the effectiveness of this strategy by ensuring oscillations do not grow.
\end{abstract}

Keywords: doubly fed induction generator; power system transients; subsynchronous control interaction; series compensation; wind farms

\section{Introduction}

Power generation is shifting towards using renewable energy sources at an accelerating pace driven by climate concerns, decreasing costs, and the depletion of fossil fuels. According to the International Energy Agency (IEA), an additional 22,101 TWh is expected to be generated from renewable sources by 2040 while non-renewable energy generation is expected to drop by 9664 TWh in the same period [1]. Global wind power capacity is now $743 \mathrm{GW}$ with the $93 \mathrm{GW}$ installed in 2020 according to the Global Wind Energy Council (GWEC) [2].

Most recent wind turbine (WT) installations are of Type-3, which employ a doubly fed induction generator (DFIG) with two back-to-back converters connecting the rotor side to the grid side [3]. Integration of wind turbines into the grid comes with issues that can be mainly categorized into two main types: operational issues and dynamic issues. The operational issues are related to the intermittent nature of wind energy whereas the dynamic issues are mostly related to fault handling [4], inter-area oscillations [5], resonances (both electrical and electromechanical), and interactions [6].

Subsynchronous control interaction (SSCI) is a purely electric phenomenon caused by an interaction between Type-3 WTs and series compensation that is similar to the well-known interaction between thermal generators and series compensation. SSCI can be considered a device-dependent subsynchronous oscillation (DDSO) [7]. The main difference between SSCI and subsynchronous resonance (SSR) is that the voltage-sourced converters (VSCs) found in the DFIG configuration actively participate in SSCIs. The first reported incidents occurred in Minnesota in 2007 [8], while the most recent incident was reported in Great Britain in 2019 [9].

Multiple methods have been proposed to mitigate SSCI in WTs. These methods vary depending on the stage of implementation at which they can be implemented, e.g., in the system planning stage, operation stage, or in the active damping control stage [10]. The 
authors of [11] propose reducing the percentage of series compensation which limits the power transfer capability of the transmission line. The authors of [12] show that installing additional Type-4 WTs in Type-3 WFs can damp the oscillations. The author of [13] proposes a damping control algorithm using static synchronous compensators (STATCOMs) and static synchronous series compensators (SSSCs). The authors of [14] address weak grid instability through the installation of VSC HVDC lines. All of these methods are expensive. The authors of [15] propose a method to prevent SSCI by bypassing the series capacitor once subsynchronous currents are detected. The authors [16] developed an algorithm that detects oscillations once subsynchronous currents exceed certain predefined reference values. This method is inexpensive but does require a communication signal to the series capacitor.

The authors of [17] propose an adaptive supplementary controller based on multiplemodel adaptive control (MMAC) to mitigate SSCI. The aim of the controller is to move the unstable modes to the left-hand plane, thus stabilizing the system by reducing the controller gain values. The authors of [18] propose a linear-quadratic controller (LQR) controller using a full-state observer. The authors of [19] propose an observer-based controller using optimal quadratic technique. The main problem with auxiliary controllers is the choice of the control signal to be used. The authors of [20] propose a simple proportional controller to mitigate SSCI. However, it uses the speed of the turbine as an input signal which can be difficult to obtain due to the disparity in the location of wind turbines. A summary of the mitigation methods is shown in Table 1.

Table 1. Summary of mitigation methods for SSCI.

\begin{tabular}{|c|c|c|}
\hline Method & Advantages & Disadvantages \\
\hline $\begin{array}{l}\text { Reducing series compensa- } \\
\text { tion [11] }\end{array}$ & $\begin{array}{l}\text { - Inexpensive solution } \\
\text { - Does not require additional equip- } \\
\text { ment }\end{array}$ & $\begin{array}{l}\text { - Limits power transfer capability } \\
\text { - Does not mitigate SSCI in all conditions }\end{array}$ \\
\hline $\begin{array}{l}\text { Installation of Type- } 4 \text { WTs in } \\
\text { Type-3 WFs [12] }\end{array}$ & - Improves damping of oscillations & $\begin{array}{l}\text { - Expensive solution } \\
\text { - Complicates modeling of WF }\end{array}$ \\
\hline $\begin{array}{l}\text { Damping control algorithm us- } \\
\text { ing STATCOM and SSSC [13] }\end{array}$ & $\begin{array}{l}\text { - Convenient solution if STATCOM or } \\
\text { SSSC is already installed }\end{array}$ & - Expensive solution \\
\hline $\begin{array}{l}\text { Installation of VSC HVDC } \\
\text { lines [14] }\end{array}$ & - Improves stability of grid & - Expensive solution to install \\
\hline $\begin{array}{l}\text { Bypass series capacitor upon de- } \\
\text { tection of subsynchronous cur- } \\
\text { rents [15] }\end{array}$ & $\begin{array}{l}\text { - Inexpensive solution } \\
\text { - Protects series capacitor }\end{array}$ & $\begin{array}{l}\text { - Requires communication signal to the series capaci- } \\
\text { tor } \\
\text { - Limits power transfer capability }\end{array}$ \\
\hline Auxiliary controller [17-20] & - Inexpensive solution & $\begin{array}{l}\text { - Depends on control signals that are hard to obtain } \\
\text { - Requires complicated communication signals }\end{array}$ \\
\hline
\end{tabular}

This paper proposes the use of frequency scans to change the inner current loop gain values or the operating conditions of the WT to mitigate SSCI. The frequency scan is conducted online by optimizing the harmonic injection phase angles to ensure minimum disruption of the steady-state operation. The proposed method is simulated using PSCAD/EMTDC software on the modified IEEE second benchmark model for subsynchronous resonance [21] to accommodate the addition of Type-3 WTs instead of conventional generators.

This paper is structured as follows: Section 2 provides an overview of DFIG configuration with its control loops. Frequency scans with the optimization method are explained in Section 3. Simulation results for three mitigation scenarios in comparison with the normal case are discussed in Section 4, discussion of the results is in Section 5, and conclusions are presented in Section 6. 


\section{Doubly Fed Induction Generator Configuration}

Type-3 WTs are based on the DFIG configuration where the stator is directly connected to the grid, and the rotor is connected to the grid through back-to-back VSCs as shown in Figure 1. These converters can supply the rotor with a variable frequency and three-phase voltages. This configuration allows for complete control of real power and reactive power.

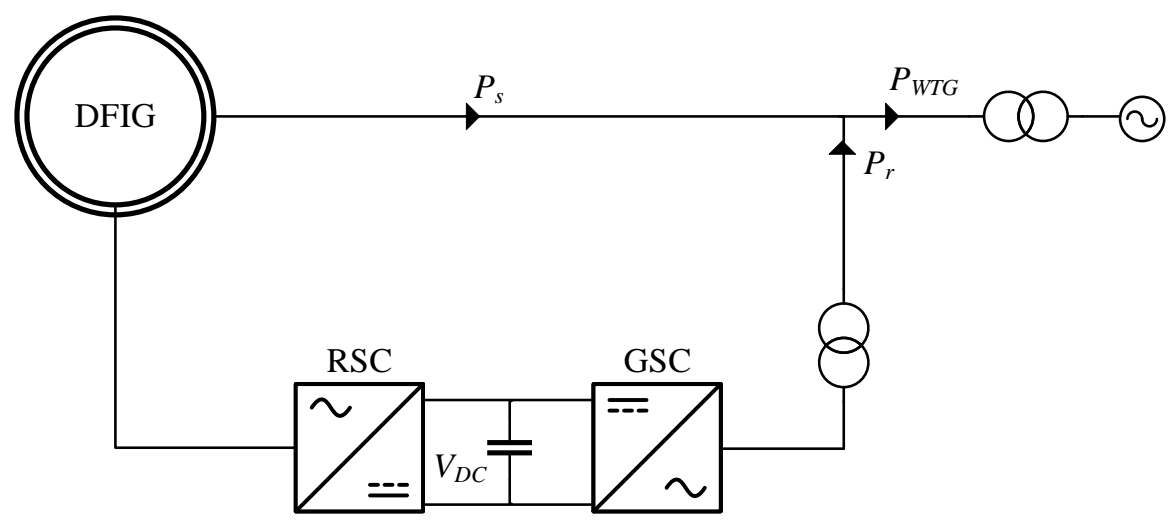

Figure 1. DFIG block diagram, two back-to-back converters connect the rotor to the grid, and the stator is directly connected to the grid.

The rotor-side converter (RSC) is responsible for both real power and reactive power [22] through the control of the stator real power $P_{s}$ and the stator reactive power $Q_{s}$ provided by the DFIG. The grid-side converter (GSC) is responsible for maintaining the DC link voltage and the grid-side reactive power at the point of common coupling (PCC). Both RSC and GSC use PI controllers as shown in Figures 2 and 3, respectively. The reference currents in the dq domain are obtained in the outer control loop while the inner control loop controls the rotor and grid voltages through the reference and actual current values. The authors of [23-26] show that the RSC loop has a higher impact on SSCI than on the GSC loop as well as the fact that the proportional gain in the inner control loop has a greater influence on impedance, highlighted in the red dashed box in Figure 2.

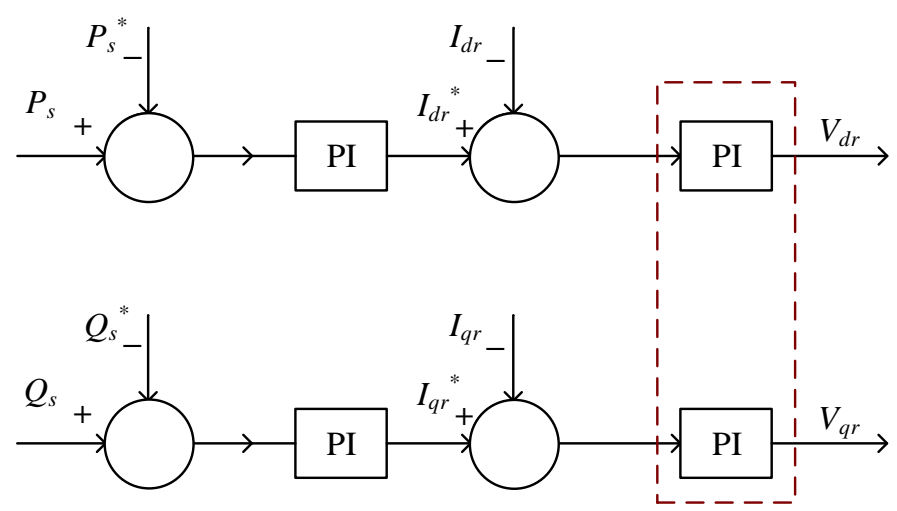

Figure 2. RSC control loops: stator real power (top loop), and stator reactive power (bottom loop). Reference values labeled with *. 

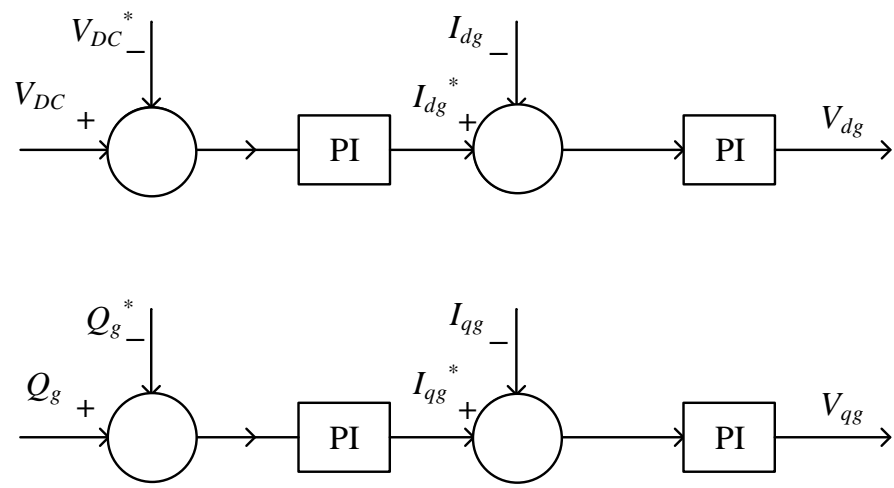

Figure 3. GSC control loops: DC bus voltage (top loop), and grid-side reactive power (bottom loop). Reference values labeled with *.

\section{Frequency Scan}

Frequency scan is the most prominent method for studying SSCI when it comes to dealing with black-box models due to it having an input-output relationship. Black-box models are typically provided by wind turbine manufacturers to protect their intellectual property. Frequency scan uses the concept of harmonic injection where a current/voltage harmonic is superimposed as an input at a certain frequency, and the output related to that input is measured to obtain the impedance value.

The harmonic injection can either be at a single frequency or at a combination of multiple frequencies where injecting frequencies individually would yield the most accurate results due to the possibility of harmonic injection distortion in a multifrequency injection [27]. Using the frequency scan method to study SSCI, the system would be split into two separate systems, i.e., grid side and WF side, and the frequency scan would take place at the point of interconnection (POI), as illustrated in Figure 4.

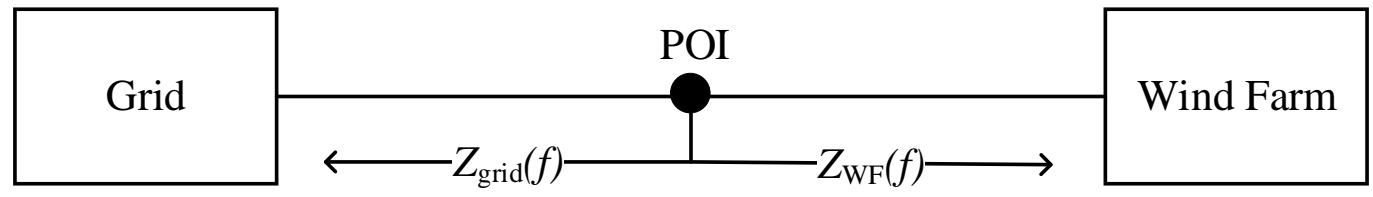

Figure 4. Illustration of frequency scan system split.

The frequency range in SSCI is less than in the fundamental frequency $(60 \mathrm{~Hz})$, so the frequency range is from $1 \mathrm{~Hz}$ to $60 \mathrm{~Hz}$. The impedances of both sides are:

$$
\begin{aligned}
Z_{\text {grid }}(f) & =R_{\text {grid }}(f)+j * X_{\text {grid }}(f) \\
Z_{\mathrm{WF}}(f) & =R_{\mathrm{WF}}(f)+j * X_{\mathrm{WF}}(f)
\end{aligned}
$$

Once those impedance values are calculated, then the entire system resistance and reactance can be obtained using:

$$
\begin{aligned}
& R_{\text {system }}(f)=R_{\text {grid }}(f)+R_{\mathrm{WF}}(f) \\
& X_{\text {system }}(f)=X_{\text {grid }}(f)+X_{\mathrm{WF}}(f)
\end{aligned}
$$

The frequency value where there might be a risk of SSCI $\left(f_{\mathrm{SSCI}}\right)$ is defined as:

$$
X_{\text {system }}\left(f_{\text {SSCI }}\right)=0 \quad \& \quad \frac{d}{d f} X_{\text {system }}\left(f_{\text {SSCI }}\right)>0
$$

The risk is confirmed if the resistance at this frequency $\left(f_{\mathrm{SSCI}}\right)$ is:

$$
R_{\text {system }}\left(f_{\mathrm{SSCI}}\right)<0
$$


Frequency scan is ideally conducted in a single frequency injection setup to avoid any harmonic injection distortion, especially with nonlinear components [27]. The main reason why harmonic injection distortion is a major issue with nonlinear components is the disruption of the operating region.

Once the voltage value exceeds a certain limit, then either the IGBT goes into a breakdown region or the response becomes nonlinear, which is undesirable. Therefore, when subjecting the WF to harmonic injection, the amplitude must not be large enough to disrupt the operating region of the IGBTs, hence the ideal setup for frequency scan is a single frequency injection where the amplitude is not too high that the ratio between voltage and current remains intact, and the impedance value can be obtained for that frequency.

However, single frequency injection is highly time consuming and is not applicable as an online tool since it only handles one frequency at a time. If multifrequency injection is to be used, then the injected voltage is:

$$
V_{\text {injected }}(\delta)=A \sum_{n=n_{\min }}^{n_{\max }} \sin \left(2 \pi f_{n} t+\delta_{n}\right)
$$

where $A$ is the amplitude of the injected harmonic;

$f_{n}$ is the injected harmonic frequency;

$\delta_{n}$ is the phase shift of the injected harmonic at $f_{n}$;

$n_{\min }, n_{\max }$ is the lowest/highest frequency of interest.

An optimization problem can be defined to reduce the peak of the injected signal by optimizing the phase angles of each frequency where the formulation for the optimization problem is:

$$
\begin{array}{ll}
\underset{\delta}{\operatorname{minimize}} & \max \left|V_{\text {injected }}(\delta)\right| \\
\text { subject to } & f_{1 \mathrm{n}}=-\delta_{n} \leq 0^{\circ} \\
& f_{2 \mathrm{n}}=\delta_{n}-360^{\circ} \leq 0^{\circ}
\end{array}
$$

The constraints are there to ensure that only positive phase shifts that are less than or equal to $360^{\circ}$ due to PSCAD/EMTDC requirements are obtained. These constraints can be relaxed since the sinusoidal function is a periodic function. The authors of $[28,29]$ propose the usage of a Schroeder equation to minimize the peak value in the injected signal, however, it yields higher peak values than the optimization method. The authors of [30] approach the optimization problem using the crest factor as a parameter that yields the same results since the RMS value is fixed for the combination of the sinusoidal function.

Using the results of optimization in Equation (8), the resulting voltage signal is shown in yellow in Figure 5, where the peak voltage is $7.68 \mathrm{kV}$, which is significantly lower than $30.68 \mathrm{kV}$ if all frequencies are to be injected at the same phase angle, as shown in the same figure. 


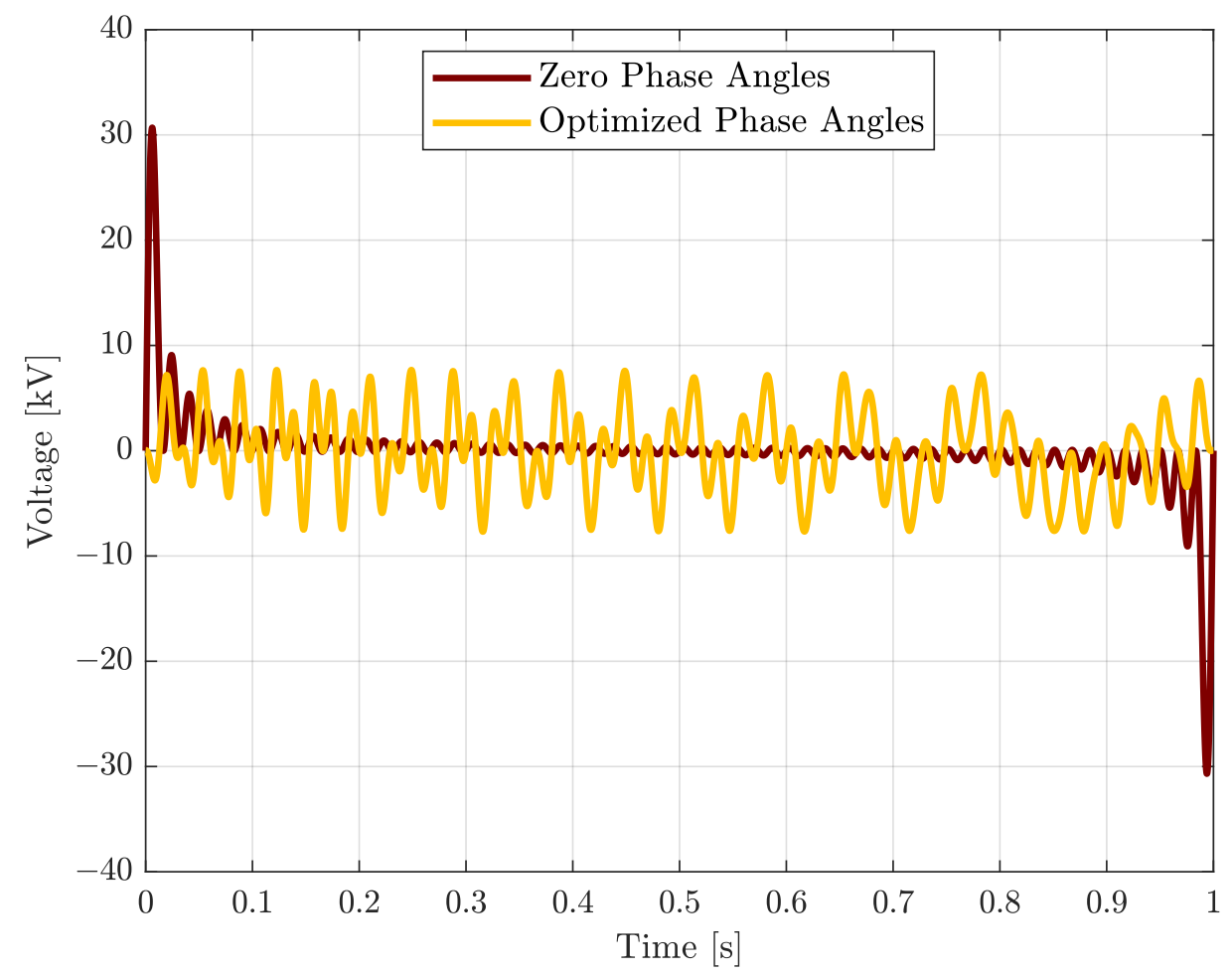

Figure 5. Multifrequency injection signal from $1 \mathrm{~Hz}$ to $60 \mathrm{~Hz}$ with zero phase angles (red), and optimized phases (yellow).

\section{Performance Evaluation}

Multiple frequency scans are conducted to obtain a look-up table for the WF. Proportional gains are varied from 0.5 to 10 in 0.5 increments, and the WF impedance $Z_{W F}$ is obtained for all values. It is then combined with a fixed $30 \%$ compensation to investigate the effect on crossover frequency and resistance magnitude at the crossover frequency as listed in Table 2.

Table 2. $K_{\mathrm{p}_{\mathrm{DQ}}}$ variations.

\begin{tabular}{cccccc}
\hline$K_{\mathrm{p}_{\mathrm{DQ}}}$ & $f_{\mathrm{SSCI}}[\mathrm{Hz}]$ & $\boldsymbol{R}\left(f_{\mathrm{SSCI}}\right)[\Omega]$ & $\boldsymbol{K}_{\mathrm{p}_{\mathrm{DQ}}}$ & $f_{\mathrm{SSCI}}[\mathrm{Hz}]$ & $\boldsymbol{R}\left(f_{\mathrm{SSCI}}\right)[\Omega]$ \\
\hline 0.50 & - & - & 1.00 & 13.7 & -2.041 \\
1.50 & 14.2 & -4.971 & 2.00 & 14.4 & -7.007 \\
2.50 & 14.4 & -8.299 & 3.00 & 14.2 & -8.867 \\
3.50 & 14.1 & -9.538 & 4.00 & 14.2 & -10.198 \\
4.50 & 14.1 & -10.618 & 5.00 & 14.0 & -10.673 \\
5.50 & 13.9 & -10.964 & 6.00 & 14.0 & -11.396 \\
6.50 & 14.1 & -11.620 & 7.00 & 13.9 & -11.422 \\
7.50 & 13.9 & -11.814 & 8.00 & 14.1 & -12.272 \\
8.50 & 13.9 & -12.178 & 9.00 & 14.0 & -12.332 \\
9.50 & 14.0 & -12.586 & 10.00 & 13.9 & -12.319 \\
\hline
\end{tabular}

Variations in $K_{\mathrm{P}_{\mathrm{DQ}}}$ have no effect on the crossover frequency, however, the resistance magnitude increases with the increased gain. Setting the proportional gain in both $d q$-axis PI controllers to 0.5 eliminates the risk of SSCI.

Another frequency scan is conducted while varying the number of online turbines to observe the effect on the impedance. Due to the typical nature of black-box models in wind turbines, the operator might only have the option to modify the number of online turbines. In this setup, the number of turbines is varied between $100 \%, 50 \%, 25 \%$, and $10 \%$. The difference in the impedance is shown in Table 3 . As can be seen, reducing the 
number of online turbines significantly reduces the crossover frequency and increases the magnitude of negative resistance more significantly at higher frequencies, thus increasing the risk of SSCI.

Table 3. Online turbine variations.

\begin{tabular}{ccc}
\hline Online Turbines & $f_{\text {SSCI }}[\mathrm{Hz}]$ & $\boldsymbol{R}\left(f_{\text {SSCI }}\right)[\Omega]$ \\
\hline $100 \%$ & 14.4 & -7.007 \\
$50 \%$ & 11.8 & -10.395 \\
$25 \%$ & 9.5 & -14.712 \\
$10 \%$ & 6.4 & -16.292 \\
\hline
\end{tabular}

A frequency scan is also conducted while varying the power order of the wind farm in order to observe the effect on the impedance. This is done by multiplying the power reference order with $100 \%, 50 \%, 25 \%$, and $10 \%$, where this power reference is sent to the RSC since the RSC controller is responsible for the real power output of the wind turbine. The difference in the impedance is shown in Table 4. The difference in the impedance is almost negligible compared to the variations in the number of online turbines in the lower frequency range and becomes significant as frequency increases.

Table 4. Power order variations.

\begin{tabular}{ccc}
\hline Power Order & $f_{\text {SSCI }}[\mathrm{Hz}]$ & $R\left(f_{\text {SSCI }}\right)[\Omega]$ \\
\hline $100 \%$ & 14.4 & -7.007 \\
$50 \%$ & 14.3 & -6.963 \\
$25 \%$ & 14.3 & -7.081 \\
$10 \%$ & 14.3 & -7.123 \\
\hline
\end{tabular}

The approach to mitigate SSCI using the online frequency scan is the following, as illustrated in Figure 6:

(1) Once SSCI is detected, the proportional gains of the $d q$-axis are reduced to near zero values (0.03) to prevent oscillations from growing exponentially.

(2) Parallel scan is enabled to identify grid impedance.

(3) Grid impedance is combined with WF impedance to obtain the overall system impedance.

(4) External or internal parameters are changed to mitigate the risk of SSCI.

In the simulated system in PSCAD, the following takes place:

(1) The system is started with Line \#2 in service.

(2) At $t=1 \mathrm{~s}$, Line \#2 trips.

(3) Once SSCI is detected, proportional gains are reduced.

(4) Parallel scan is enabled.

(5) Parallel scan results are processed.

(6) Parameters are changed to mitigate SSCI. 


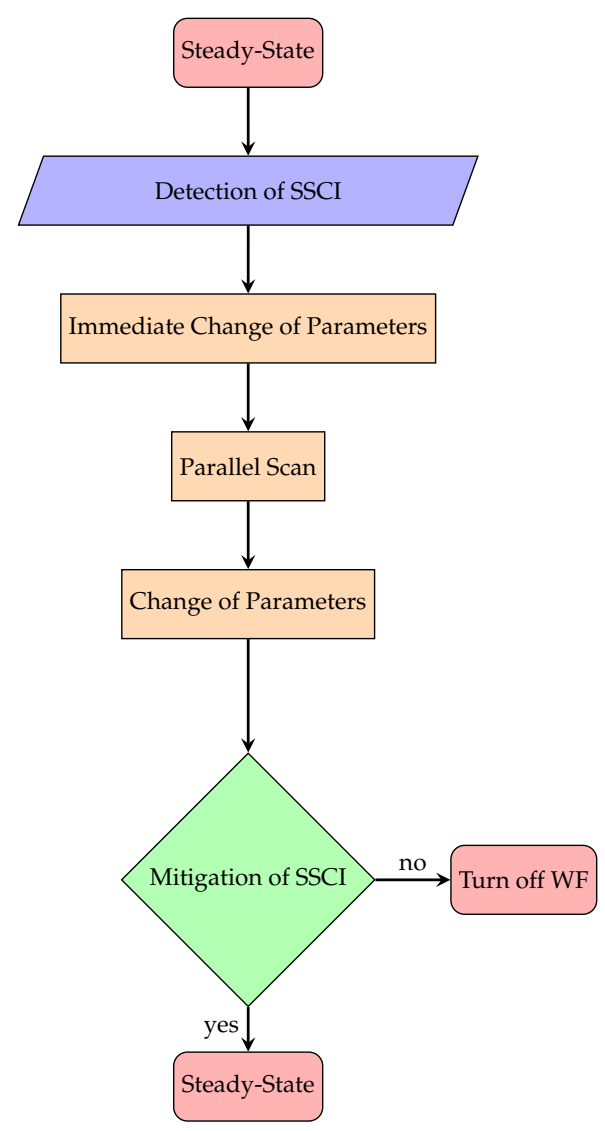

Figure 6. Flowchart of SSCI mitigation approach.

\subsection{Output Power Exceeds $1.050 \mathrm{pu}$}

In the first approach, SSCI is detected once the output power of the WF exceeds 1.050 of the steady-state power output. Figure 7 shows the RMS voltage, real power, and reactive power waveforms. The line trips at $t=1.00 \mathrm{~s}$, leaving the WF in a radial connection with the series-compensated line, and at $t=1.10 \mathrm{~s}, \mathrm{SSCI}$ is detected when the power output is $210 \mathrm{MW}$ at which point the parameters are decreased, and parallel scan is enabled. At $t=2.10 \mathrm{~s}$, parallel scan is disabled, and a stable operating point is obtained. The maximum real power during the oscillations is $211.09 \mathrm{MW}$, and the minimum is $183.00 \mathrm{MW}$ with the reactive power ranging between -25.17 and 8.87 MVAr.

\subsection{Output Power Exceeds 1.025 pu}

In the second approach, SSCI is detected once the output power of the WF exceeds 1.025 of the steady-state power output. Figure 8 shows the RMS voltage, real power, and reactive power waveforms. The line trips at $t=1.00 \mathrm{~s}$, leaving the WF in a radial connection with the series-compensated line, and at $t=1.06 \mathrm{~s} \mathrm{SSCI}$ is detected when the power output is $205 \mathrm{MW}$ at which point the parameters are decreased, and parallel scan is enabled. At $t=2.06 \mathrm{~s}$, parallel scan is disabled, and a stable operating point is obtained. The maximum real power during the oscillations is $209.75 \mathrm{MW}$, and the minimum is $189.35 \mathrm{MW}$ with the reactive power ranging between -15.96 and 3.82 MVAr. 

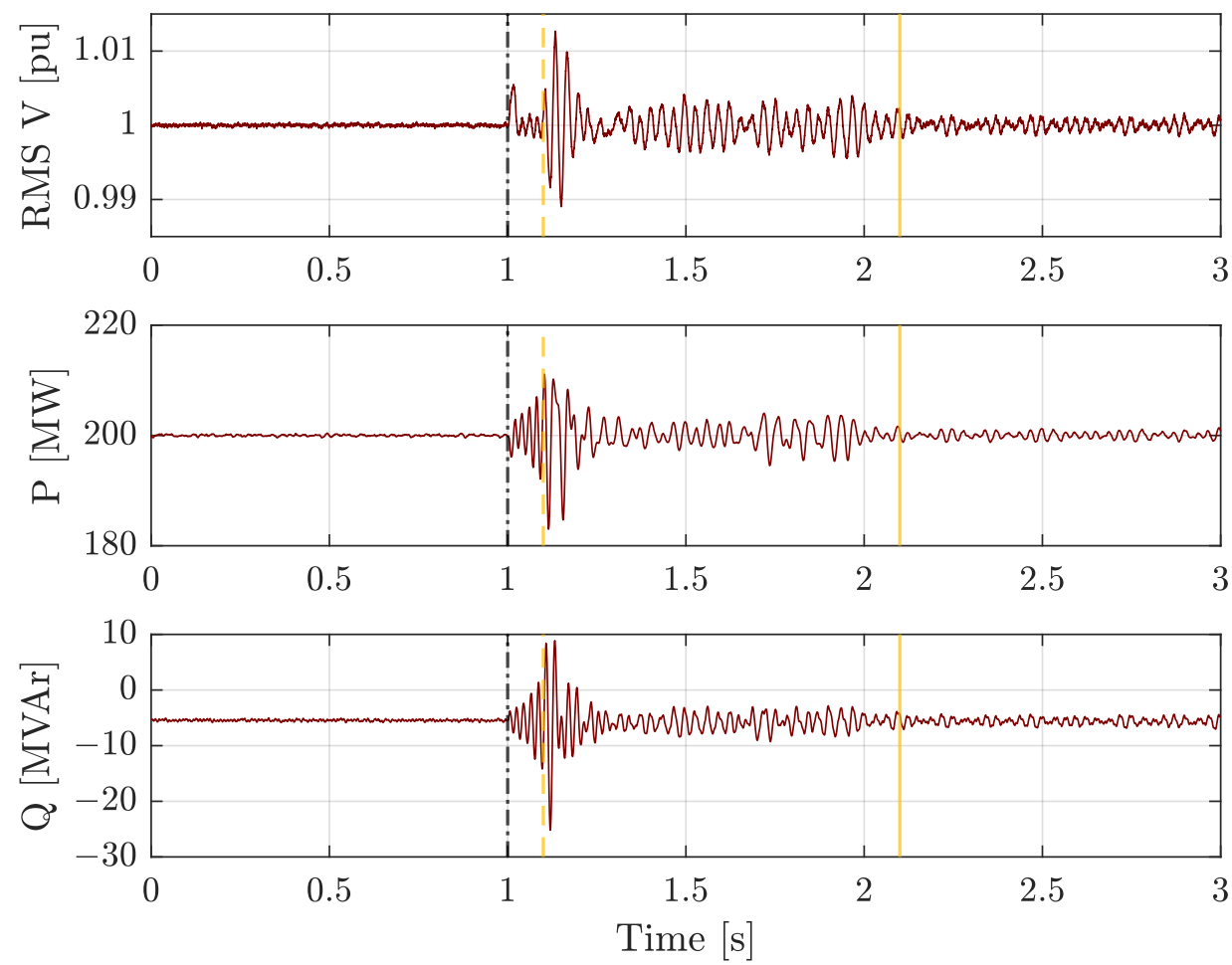

Figure 7. RMS voltage, real power, and reactive power waveforms when output power exceeds $1.050 \mathrm{pu}$. (black dashed line is when Line \#2 trips, yellow dashed line is when SSCI is detected, and yellow straight line is when a stable operating point is found).
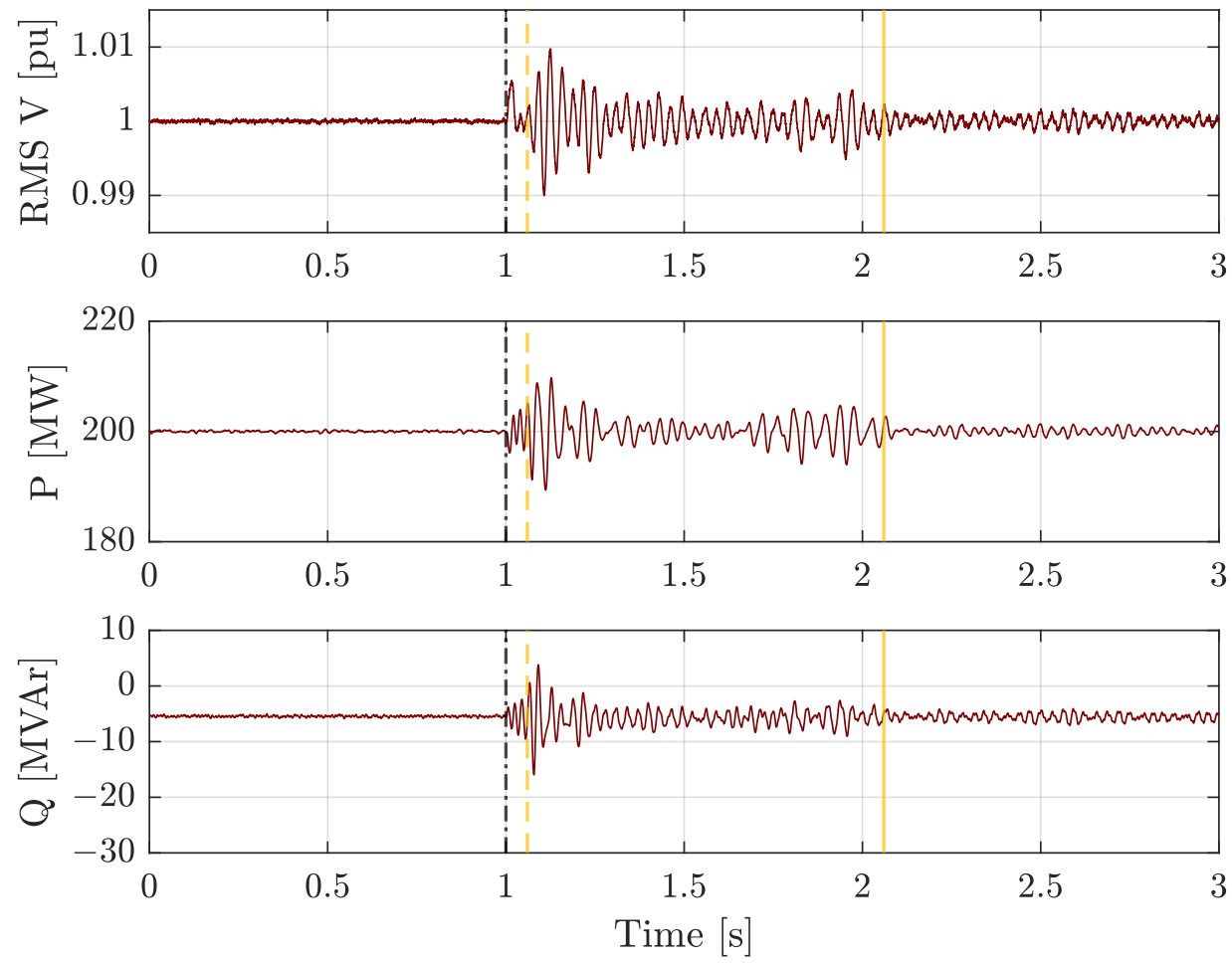

Figure 8. RMS voltage, real power, and reactive power waveforms when output power exceeds 1.025 pu. (black dashed line is when Line \#2 trips, yellow dashed line is when SSCI is detected, and yellow straight line is when a stable operating point is found). 


\subsection{Access to External Signal}

In the third approach, it is assumed that the WF has access to the tripping signal of the $\mathrm{CB}$ associated with Line \#2. Figure 9 shows the RMS voltage, real power, and reactive power waveforms. The line trips at $t=1.00 \mathrm{~s}$, leaving the $\mathrm{WF}$ in a radial connection with the series-compensated line, at $t=1.00 \mathrm{~s}, \mathrm{SSCI}$ is detected when the CB is open at which point the parameters are decreased, and parallel scan is enabled. At $t=2.00 \mathrm{~s}$, parallel scan is disabled, and a stable operating point is obtained. The maximum real power during the oscillations is $209.28 \mathrm{MW}$ and the minimum is $190.73 \mathrm{MW}$ with the reactive power ranging between -8.95 and -2.52 MVAr.
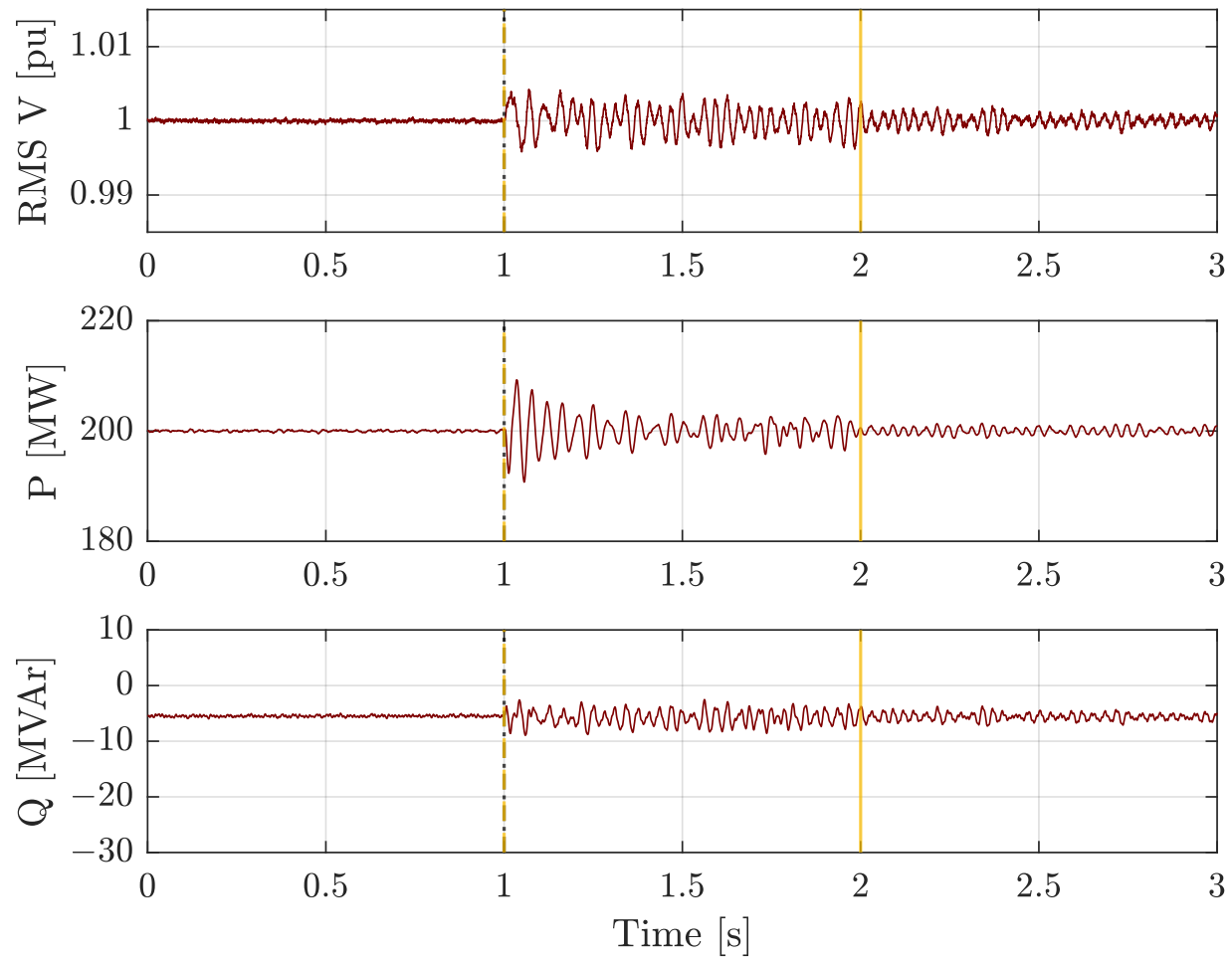

Figure 9. RMS voltage, real power, and reactive power waveforms with access to external signal. (black dashed line is when Line \#2 trips, yellow dashed line is when SSCI is detected, and yellow straight line is when a stable operating point is found).

The normal operation without any mitigation approach yields an undamped oscillation that grows to $858 \mathrm{MW}$ before the rotor stops spinning due to growing subsynchronous currents. Figure 10 shows the real power output in the normal operation without any mitigation in comparison to three mitigation approaches. 


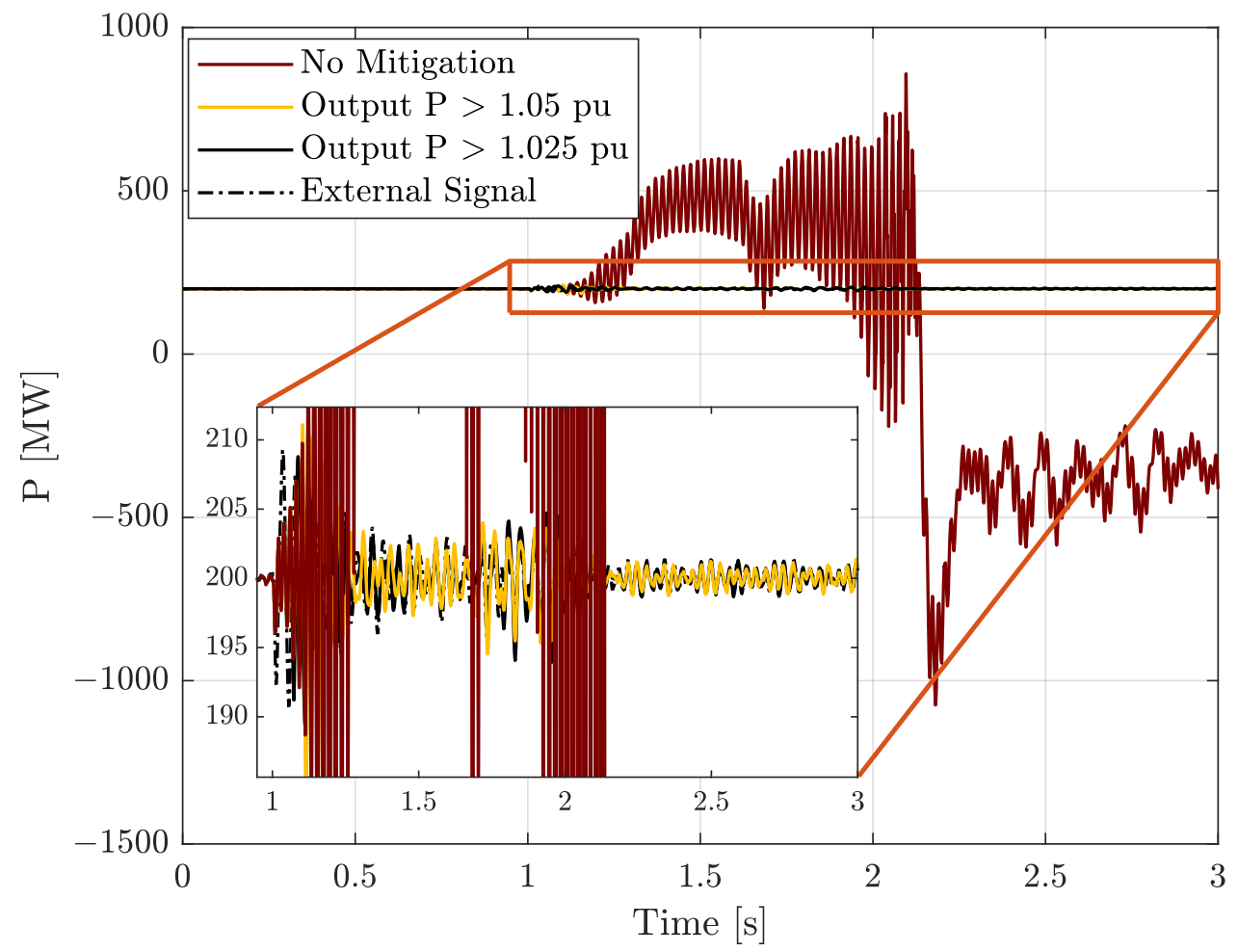

Figure 10. Comparison between no mitigation operation and the three mitigation approaches. Oscillations grow to $500 \mathrm{MW}$ in $0.5 \mathrm{~s}$ without any mitigation.

\section{Discussion}

SSCI is mitigated in all of the three approaches: (i) output power exceeds $1.050 \mathrm{pu}$, (ii) output power exceeds $1.025 \mathrm{pu}$, and (iii) access to external signal. Real power oscillation is the most significant in the first approach (output power exceeds $1.050 \mathrm{pu}$ ), and the least significant in the third approach (access to external signal). Once a stable operating point is obtained, in all of the previously mentioned approaches, the real power oscillation is less than $0.70 \%$. Reactive power oscillations are minimized and the RMS voltage ranges between $0.998 \mathrm{pu}$ and $1.002 \mathrm{pu}$. In the normal operation without any mitigation approach, the output power grows to $400 \mathrm{MW}$ in less than $0.30 \mathrm{~s}$, which is double the set point of 200 MW. This can either lead to excessive damage in WTs or to the disconnection of the $\mathrm{WF}$, and both of these scenarios lead to an undesired disruption of service.

\section{Conclusions}

This work shows how frequency scans can be optimized and utilized as an online frequency scanning tool to mitigate SSCI in WFs. Future research can look into replacing the lookup table that needs to be obtained with parametric equations. Further research can also investigate other parameters and their influence on the impedance of the WF. A lookup table needs to be obtained which can be replaced in the future with parametric equations to overcome the lookup table requirement. Simulation results are shown to illustrate the obtained steady-state operating point after the radial connection between the WF and the series compensated line. This mitigation approach is sufficient to ensure that the WF remains in operation until the fault/outage leading to the radial connection has been addressed. 
Author Contributions: Both authors conceptualized the work. F.A. performed writing, analysis, and material gathering. A.M.-S. edited the work. Both authors have read and agreed to the published version of the manuscript.

Funding: This research was funded through a Fulbright Foreign Student Program scholarship. This work is also supported in part by Manitoba Hydro International and in part by National Science Foundation under award ECCS-1509895.

Institutional Review Board Statement: Not applicable.

Informed Consent Statement: Not applicable.

Data Availability Statement: Not applicable.

Conflicts of Interest: The authors declare no conflict of interest.

\section{References}

1. International Energy Agency. World Energy Outlook 2020; IEA: Paris, France, 2020. Available online: https:/ /www.iea.org/ reports/world-energy-outlook-2020 (accessed on 3 May 2021).

2. Global Wind Energy Council. Global Wind Report 2021; Global Wind Energy Council: Brussels, Belgium, 2021. Available online: https:/ / gwec.net/global-wind-report-2021/ (accessed on 3 May 2021).

3. Muljadi, E.; Zhang, Y.C.; Gevorgian, V.; Kosterev, D. Understanding dynamic model validation of a wind turbine generator and a wind power plant. In Proceedings of the 2016 IEEE Energy Conversion Congress and Exposition (ECCE), Milwaukee, WI, USA, 18-22 September 2016; pp. 1-5. [CrossRef]

4. Mohammadhassani, A.; Skoff, N.; Mehrizi-Sani, A. Performance Analysis of Distance Protection in Presence of Type III Wind Turbine Generators. In Proceedings of the 2021 IEEE Power \& Energy Society Innovative Smart Grid Technologies Conference (ISGT), Washington, DC, USA, 16-18 February 2021; pp. 1-5. [CrossRef]

5. Zhang, C.; Ke, D.; Sun, Y.; Chung, C.Y.; Xu, J.; Shen, F. Coordinated Supplementary Damping Control of DFIG and PSS to Suppress Inter-Area Oscillations with Optimally Controlled Plant Dynamics. IEEE Trans. Sustain. Energy 2018, 9, 780-791. [CrossRef]

6. Fan, L.; Kavasseri, R.; Miao, Z.L.; Zhu, C. Modeling of DFIG-Based Wind Farms for SSR Analysis. IEEE Trans. Power Deliv. 2010, 25, 2073-2082. [CrossRef]

7. IEEE Ssr Working Group. Reader's guide to subsynchronous resonance. IEEE Trans. Power Syst. 1992, 7, 150-157. [CrossRef]

8. Mulawarman, A.; Mysore, P. Detection of Undamped Sub-Synchronous Oscillations of Wind Generators with Series Compensated Lines. In Proceedings of the Minnesota Power Systems Conference, Minneapolis, MN, USA, 1-3 November 2011.

9. Jiang, H.; Ma, S.; Song, R.; Xiang, Z. Analysis on subsynchronous oscillation stability for large scale offshore wind integration. Energy Rep. 2020, 6, 189-195. [CrossRef]

10. Shair, J.; Xie, X.; Yan, G. Mitigating subsynchronous control interaction in wind power systems: Existing techniques and open challenges. Renew. Sustain. Energy Rev. 2019, 108, 330-346. [CrossRef]

11. Zhu, C.; Hu, M.; Wu, Z. Parameters impact on the performance of a double-fed induction generator-based wind turbine for subsynchronous resonance control. IET Renew. Power Gener. 2012, 6, 92-98. [CrossRef]

12. An, Z.; Shen, C.; Zheng, Z.; Liu, F.; Chang, X.; Wei, W. Scenario-based analysis and probability assessment of sub-synchronous oscillation caused by wind farms with direct-driven wind generators. J. Modern Power Syst. Clean Energy 2019, 7, 243-253. [CrossRef]

13. El-Moursi, M.S. Mitigating subsynchronous resonance and damping power system oscillation in a series compensated wind park using a novel static synchronous series compensator control algorithm. Wind Energy 2012, 15, 363-377. [CrossRef]

14. Zhang, L.; Harnefors, L.; Nee, H. Interconnection of Two Very Weak AC Systems by VSC-HVDC Links Using PowerSynchronization Control. IEEE Trans. Power Syst. 2011, 26, 344-355. [CrossRef]

15. Lasher, W.; Carter, C.; Daniel, J.; Martin, D.; Wong, W.; Koessler, R. Analysis of Reactive Compensation Design for the Competitive Renewable Energy Zones Transmission Plan in Texas; ABB: Quebec City, QC, Canada, 2010

16. Xie, X.; Liu, W.; Liu, H.; Du, Y.; Li, Y. A System-Wide Protection against Unstable SSCI in Series-Compensated Wind Power Systems. IEEE Trans. Power Deliv. 2018, 33, 3095-3104. [CrossRef]

17. Ghaffarzdeh, H.; Mehrizi-Sani, A. Mitigation of Subsynchronous Resonance Induced by a Type III Wind System. IEEE Trans. Sustain. Energy 2020, 11, 1717-1727. [CrossRef]

18. Ghafouri, M.; Karaagac, U.; Karimi, H.; Jensen, S.; Mahseredjian, J.; Faried, S.O. An LQR Controller for Damping of Subsynchronous Interaction in DFIG-Based Wind Farms. IEEE Trans. Power Syst. 2017, 32, 4934-4942. [CrossRef]

19. Mohammadpour, H.A.; Santi, E. SSR Damping Controller Design and Optimal Placement in Rotor-Side and Grid-Side Converters of Series-Compensated DFIG-Based Wind Farm. IEEE Trans. Sustain. Energy 2015, 6, 388-399. [CrossRef]

20. Huang, P.; el Moursi, M.S.; Xiao, W.; Kirtley, J.L. Subsynchronous Resonance Mitigation for Series-Compensated DFIG-Based Wind Farm by Using Two-Degree-of-Freedom Control Strategy. IEEE Trans. Power Syst. 2015, 30, 1442-1454. [CrossRef]

21. Second Benchmark Model for Computer Simulation of Subsynchronous Resonance. IEEE Trans. Power Appar. Syst. 1985, PAS-104, 1057-1066. [CrossRef] 
22. Abad, G.; Lopez, J.; Rodriguez, M.; Marroyo, L.; Iwanski, G. Doubly Fed Induction Machine: Modeling and Control for Wind Energy Generation; John Wiley \& Sons: Hoboken, NJ, USA, 2011; Volume 85.

23. Gu, K.; Wu, F.; Zhang, X.-P. Sub-synchronous interactions in power systems with wind turbines: A review. IET Renew. Power Gener. 2019, 13, 4-15. [CrossRef]

24. Daniel, J.; Wong, W.; Ingestrom, G.; Sjoberg, J. Subsynchronous phenomena and wind turbine generators. In Proceedings of the PES T\&D 2012, Orlando, FL, USA, 7-10 May 2012; pp. 1-6. [CrossRef]

25. Fan, L.; Miao, Z. Mitigating SSR Using DFIG-Based Wind Generation. IEEE Trans. Sustain. Energy 2012, 3, 349-358. [CrossRef]

26. Mohammadpour, H.A.; Santi, E. Sub-synchronous resonance analysis in DFIG-based wind farms: Definitions and problem identification-Part I. In Proceedings of the 2014 IEEE Energy Conversion Congress and Exposition (ECCE), Pittsburgh, PA, USA, 14-18 September 2014; pp. 812-819. [CrossRef]

27. Jiang, X.; Gole, A.M. A frequency scanning method for the identification of harmonic instabilities in HVDC systems. IEEE Trans. Power Deliv. 1995, 10, 1875-1881. [CrossRef]

28. Kulkarni, A.M.; Das, M.K.; Gole, A.M. Frequency scanning analysis of STATCOM-Network interactions. In Proceedings of the 2016 IEEE 6th International Conference on Power Systems (ICPS), New Delhi, India, 4-6 March 2016; pp. 1-6. [CrossRef]

29. Pintelon, R.; Schoukens, J. System Identification: A Frequency Domain Approach; John Wiley \& Sons: Hoboken, NJ, USA, 2012.

30. Matsuo, I.B.M.; Salehi, F.; Zhao, L.; Zhou, Y.; Lee, W. Optimized Frequency Scanning of Nonlinear Devices Applied to Subsynchronous Resonance Screening. IEEE Trans. Ind. Appl. 2020, 56, 2281-2291. [CrossRef] 